\title{
Galangin increases ERK1/2 phosphorylation to decrease ADAM9 expression and prevents invasion in A172 glioma cells
}

\author{
DEQIANG LEI ${ }^{*}$, FANGCHENG ZHANG, DONGXIAO YAO, NANXIANG XIONG, \\ XIAOBING JIANG and HONGYANG ZHAO* \\ Department of Neurosurgery, Union Hospital, Tongji Medical College, \\ Huazhong University of Science and Technology, Wuhan, Hubei 430022, P.R. China
}

Received July 30, 2016; Accepted June 29, 2017

DOI: $10.3892 / \mathrm{mmr} .2017 .7920$

\begin{abstract}
Galangin (3,5,7-trihydroxyflavone), is a natural flavonoid present in plants. Galangin is reported to exhibit anti-cancer properties against various cancer types. The aim of the present study was to display the effects of galangin on glioma and its mechanism of action in A172 human glioma cancer cells. The results clearly indicated that treatment of galangin inhibited A172 cell migration and invasion under non-toxic doses. A human proteinase array assay was conducted to elucidate the potential effects of galangin, and the obtained results demonstrated that treatment of galangin inhibited ADAM9 protein expression and mRNA expression, that are known to contribute to cancer progression. Sustained extracellular signal-regulated kinase (Erk)1/2 activation was also monitored, which contributed to ADAM9 protein expression and mRNA inhibition as investigated using western blotting analysis and reverse transcription-quantitative polymerase chain reaction experiment. Erk1/2 inhibition by inhibitor or small interfering (si)Erk transfection markedly terminated galangin-inhibited A172 migration and invasion via an Erk1/2 activation mechanism. Collective results suggested that galangin may act as an effective chemotherapeutic agent for glioma cancer depending on its ability to bring about ADAM9 and Erk1/2 activation.
\end{abstract}

\section{Introduction}

Gliomas are considered as one of the most harmful cancers, which frequently leads to the development of serious

Correspondence to: Dr Deqiang Lei or Dr Hongyang Zhao, Department of Neurosurgery, Union Hospital, Tongji Medical College, Huazhong University of Science and Technology, 1277 Jiefang Road, Wuhan, Hubei 430022, P.R. China

E-mail: deqianglei@hotmail.com

E-mail: hongyangzhao86@sina.com

*Contributed equally

Key words: galangin, A172, glioma cancer, ADAM9 protein expression problems and in the majority of cases patients succumb to the disease (1). There are many complications in diagnosing and treating gliomas. Gliomas can be observed mostly in children and adults aged between 50 and 60 years old (2). Malignant gliomas are therefore a crucial cause of mortality in young people and the improvement in survival rates could save the lives of many people. The common treatment is composed of a cytoreductive operation followed by radiotherapy, however the diagnosis still remains poor with a survival period of nine months and $\sim 5-10 \%$ of patients surviving up to two years (3).

Gliomas are locally aggressive tumors that have poor diagnosis even following the treatment with a combination of operation, chemotherapy and radiotherapy. Previously, there has been a small development in analyzing the molecular genetics of these brain tumors, but still the origin of cell types are uncertain and the molecular origin of tumor metastasis are not well understood (4). Clear analyses about the origination and development of disease may recognize new targets for treating tumors. Flavonoids are a class of polyphenolic compounds that are familiar constituents in the human diet. Flavonoids occur worldwide in plants and contain various beneficial characteristics. It was reported that people living in western countries are consuming a significant amount of dietary flavonoids. They are rich in antioxidant properties against cancer cells and can be used as anticancer drugs in the form of apoptosis inducers and cell proliferation inhibitors (5).

Galangin, also termed as 3,5,7-trihydroxyflavone, is a member of the flavonoids and occurs in Alpinia officinarum herbal plants that are used in Asian countries for therapeutic treatment. These plants contain a rich source of honey and the elements in this plant contains major constituents of propolis, which is a natural balsam secreted by honey bees (6-8). Galangin exhibited different pharmacological properties including antioxidative, antimutagenic and radical scavenging (9-11). Literature studies have indicated that galangin presents anticancer effects against different cancer cells such as hepatocellular carcinoma cells, colon cancer cells, ovarian cancer cells, human mammary tumor cells, melanoma, prostate cancer cells and promyelocytic leukemia cells (12-18). Galangnin-induced apoptosis through the mitochondrial pathway and G0/G1 cell cycle arrest upon the reduction of cyclins E, A9 and D310. Galangin triggered autophagy and apoptosis at different concentrations via elevation of p53 in 
HepG2 cell lines (19). TRAIL-induced apoptosis was observed in prostate cancer cells upon treatment with galangin (18). Though galangin displayed cell proliferation and apoptosis in various cancer cells, the knowledge on exact effect and its associated molecular mechanism of galangin participated in glioma cancer still remains doubtful. Hence, the authors are interested to investigate whether galangin has any potential effects against glioma cancer using the A172 glioma cancer cell line.

\section{Materials and methods}

Materials. Galangin, MTT reagent and dimethyl sulfoxide (DMSO) were acquired from Sigma-Aldrich; Merck KGaA (Darmstadt, Germany). All the antibodies used against extracellular signal-regulated kinase (Erk)1/2, p-Erk1/2, protein kinase B (AKT), p-AKT and ADAM9, secondary antibodies, $\beta$-actin and small interfering (si)ERK were obtained from Cell Signaling Technology, Inc. (Danvers, MA, USA). ADAM9 protein, MEK inhibitor (U0126) and the ARY021 human protease array kit were ordered from Abcam (Cambridge, UK).

Cell culture and methods. The A172 human glioma cancer cell line was purchased from American Type Culture Collection (Manassas, VA, USA). These cell lines were cultured in RPMI-1640 medium supplemented with 10\% FBS, penicillin and streptomycin $(100 \mathrm{U} / \mathrm{ml}+100 \mathrm{mg} / \mathrm{ml})$ and then maintained in an incubator with humidified atmosphere $\left(5 \% \mathrm{CO}_{2}\right)$ at $37^{\circ} \mathrm{C}$. Galangin $(10 \mathrm{mM})$ stock solution was prepared using DMSO solvent, kept at $-20^{\circ} \mathrm{C}$ for storage and then diluted further to carry out the other experiments.

Cytotoxicity. MTT assay was performed to determine the cell cytotoxicity. In this experiment, the human glioma cancer cell line (A172) at a density of $4 \times 10^{3}$ cells/well were cultured in 24-well plates and then treated with different galangin concentrations $(5-25 \mu \mathrm{M})$ for different time periods, 24 and $72 \mathrm{~h}$. Later, the cell lines were incubated with MTT reagent $(0.4 \mathrm{mg} / \mathrm{ml})$ for another $\sim 5 \mathrm{~h}$. Following discarding the medium, each well was added with $\sim 50 \mu 1$ isopropanol and then absorbance was measured at $590 \mathrm{~nm}$ using a spectrophotometer.

Cell migration and invasion assays. In the current assay, Matrigel was not used to coat the cell culture chambers. The experiment was carried out in such a way that the A172 cells at a density of $4 \times 10^{4}$ per well were cultured in the upper compartment using serum free medium, whereas the lower compartment was added with 10\% FBS containing Dulbecco's modified Eagle's medium (Thermo Fisher Scientific, Inc., Waltham, MA, USA). It was then treated with different galangin concentrations $(5-25 \mu \mathrm{M})$ and incubated for $6 \mathrm{~h}$. Following incubation, a cotton swab was used to clean the cells located inside the chambers and the migrated cells to the lower portion were stained using Giemsa $(0.1 \%)$. The migration was carried out via poly-vinylpyrrolidine free polycarbonate membrane with a pore size of $8 \mathrm{~mm}$. A light microscope at the magnification $\times 200$ was used for counting and non-treated cells are treated as controls.

A cell invasion assay was performed similarly to that of the cell migration assay as mentioned in previous method. In this assay, initially the chamber membranes were coated using Matrigel $(50 \mu \mathrm{g} / \mathrm{ml})$ followed by cell culturing at a density of $4 \times 10^{4}$ cells/well in the upper compartment. The cell invasion via Matrigel and polycarbonate membranes to the lower portion was recorded at $12 \mathrm{~h}$ incubation, the same way as mentioned in cell migration experiments.

Reverse transcription-quantitative polymerase chain reaction $(R T-q P C R)$. In this experiment, TRIzol plus RNA extraction kit (Invitrogen; Thermo Fisher Scientific, Inc.) was used to extract total RNAs and the synthesis of cDNAs (from $4 \times 10^{4}$ A 172 cells) was performed using cDNA synthetic kit/Superscript III Platinum One Step RTqPCR kit (Thermo Fisher Scientific, Inc.) based on previous methods presented in the reported literature (20). Briefly, TaqMan probe reaction mixture (SYBR-Green I dye from Invitrogen; Thermo Fisher Scientific, Inc.) in a standard cycling program were used along with specific forward and reverse primers (flurogenic primers) of ADAM9 (forward, 5'-GCTACGCACCTCCAAATTGT-3' and reverse $5^{\prime}$-GGCCTCAAGTCATTGGAA-3') and $\beta$-actin (forward 5'-AGTTTAGGACTTGACC-3' and reverse, 5'-TTA AGCCCTGAAATCCT-3'-designed using Primer3 program) were run in a Step One Plus RT PCR system (Applied Biosystems; Thermo Fisher Scientific, Inc.) to amplify the mRNAs of ADAM9 and $\beta$-actin. The relative fold change in mRNA expression levels were quantified using the $2^{-\Delta \Delta C q}$ method (20).

Western blot analysis. To carry out western blotting, lysis buffer [50 mM Tris- $\mathrm{HCl}$ (pH 7.5), 0.5\% sodium deoxycholate, $150 \mathrm{mM} \mathrm{NaCl}, 0.1 \%$ SDS, $1 \mathrm{mM}$ dithiothreitol, $5 \mathrm{mM}$ EDTA, $50 \mathrm{mM}$ sodium fluoride] was used to extract the cells total protein and estimated using Bradford method. Equal concentration of protein extracts $(50 \mu \mathrm{g})$ were added to each well for SDS-PAGE (10\%) separation electrotransferred onto polyvinylidene difluoride (PVDF) membranes. The membrane was blocked with TBS containing Tween-20 and $5 \%$ skimmed milk for $2 \mathrm{~h}$ at $37^{\circ} \mathrm{C}$ and incubated with primary antibodies anti-rabbit monoclonal ADAM9 (cat. no. 2099S; 1:1,000), Erk1/2 (cat. no. 4376S; 1:1,000), p-Erk1/2 (cat. no. 4370S; 1:1,000), AKT (cat. no. 4685S; 1:1,000), p-AKT (cat. no. 4060S; 1:1,200) antibodies and $\beta$-actin (cat. no. $4970 \mathrm{~S} ; 1: 1,000)$ for $2 \mathrm{~h}$ at $37^{\circ} \mathrm{C}$ and again incubated with a secondary antibody with conjugated to anti-rabbit immunoglobulin G horseradish peroxidase (cat. no. 7074S; 1:10,000) for $2 \mathrm{~h}$ at $37^{\circ} \mathrm{C}$. All the antibodies (primary/secondary) are bought from Cell Signaling Technology, Inc. The visualization of bounded proteins was determined using the enhanced chemiluminescence detection system (GE Healthcare Life Sciences, Chalfont, UK). The image/band intensity was detected using a LAS 4000 gel documentation system from GE Healthcare Life Sciences (Chalfont, UK) using Image J software from the National Institutes of Health (version 2.8; Bethesda, MD, USA).

Cell transfection. Initially, the human A172 cells were transfected using siErk with the help of Lipofectamine 2000 (Thermo Fisher Scientific, Inc.) and kept for next 2 days to undergo transfection. Once the cells were transfected, galangin was added and harvested to extract total RNA/protein. Later, 
A<smiles>O=c1c(O)c(-c2ccccc2)oc2cc(O)cc(O)c12</smiles>

C

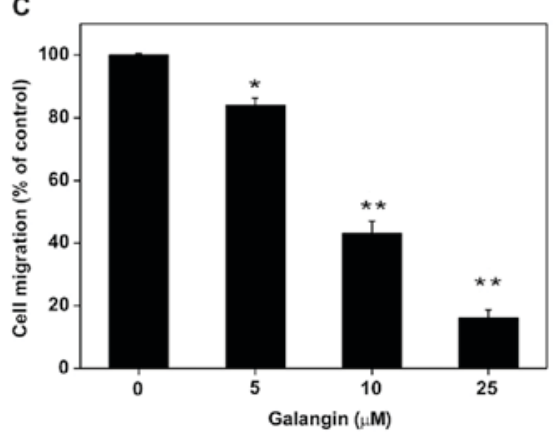

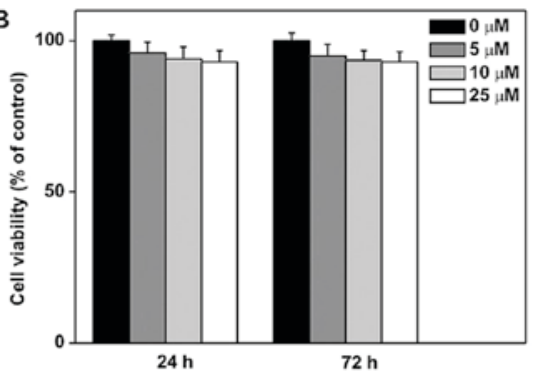

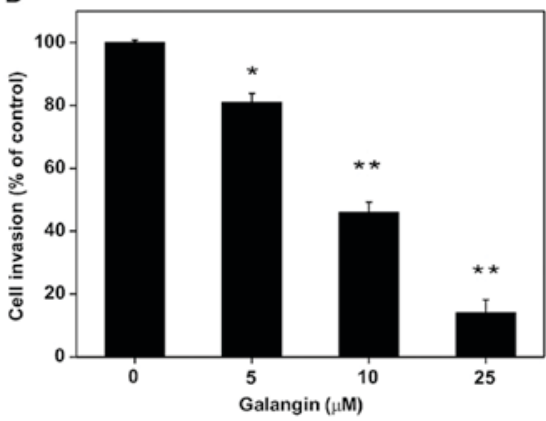

Figure 1. (A) Chemical structure of galangin and its effect on the A172 glioma cell line. (B) The A172 cells were grown with $0-25 \mu \mathrm{M}$ of galangin for 24 and $72 \mathrm{~h}$. MTT assay was used to measure the viability of the cells (C) Cell migration and (D) cell invasion were measured for $24 \mathrm{~h}$. The data are presented as the mean \pm standard error at three independent experiments. ${ }^{*} \mathrm{P}<0.05 ;{ }^{* *} \mathrm{P}<0.01$. vs. $0 \mu \mathrm{M}$ (Control).

the above discussed methods (RT-qPCR and western blot section) were used to measure the mRNA/protein levels.

Statistical analysis. All the given experimental data were expressed as mean \pm standard error of the mean. All the experiments in this work were performed independently in triplicate. Measurement of statistical differences between the groups were recorded using one-way analysis of variance followed by Dunnett's multiple comparison post hoc test with the help of GraphPad Prism software (version, 5; GraphPad Software, Inc., La Jolla, CA, USA). P $<0.05$ was considered to indicate a statistically significant difference.

\section{Results}

Cell migration and invasion assays. The investigation results of cell migration and invasion assays on A172 cells is presented in Fig. 1. The results indicated that galangin treatment reduced the A172 cell migration and invasion. In order to study the galangin effect on cell viability, MTT assay (Fig. 1B) was carried out on the A172 glioma cancer cell line. Upon treatment of the A172 cell line with galangin at different concentrations (5-25 $\mu \mathrm{M})$, no significant inhibition on A172 cell viability was observed. To elucidate the galangin potentials on A172 cell migration and invasion, a specific galangin concentration was chosen in such a way that it did not show significant effects on A172 cell growth. The data indicated that treatment of various concentrations of galangin $(5-25 \mu \mathrm{M})$ for $\sim 24 \mathrm{~h}$ on the A172 cell line markedly decreased the migration potential of the A172 cell line in a concentration dependent fashion when compared to that of non-treated cells. The percentage of migration was from 16 to $84 \%$ in A172 cells, whereas the percentage of cell invasion was from 14 to $81 \%$ (Fig. 1C and D). All these results indicated that galangin strongly inhibited A172 cell migration and invasion under non-toxic doses.
ADAM9 expression in A172 cells. The authors conducted an experiment using a human protease inhibitor array kit in order to exhibit the molecular mechanisms underlying the reducing effects of galangin on A172 cell migration and invasion. This investigation helps to display the invasion associated protein actions inside the cells. An earlier report indicated that ADAM9 has a special role in cell migration and cell invasion in glioma cancer cell lines (21). The study observed ADAM9 expression following treatment with different doses of galangin and the results clearly indicated that galangin reduced ADAM9 expression (Fig. 2A). To further elucidate the protease array results, western blot analysis and RT-qPCR was conducted using galangin and demonstrated that it hindered mRNA and ADAM9 protein expression in the A172 cell line (Fig. 2B and C). Results of these studies revealed that galangin hinders the A172 cell migration and invasion potential, which could be due to the decrease of ADAM9 protein expression. Before investigating the pharmacological properties of galangin on reduced ADAM9 expression, the authors checked whether galangin could hinder RhADAM9-induced A172 cell migration and invasion. Results presented in Fig. 2D and E clearly indicated that galangin hindered both RhADAM9-induced A172 cell migration and invasion in the A172 glioma cell line. These investigations revealed that the anti-metastatic ability of galangin results from repressing the ADAM9 expression in the A172 cell line.

Erk1/2 phosphorylation inducement in A172 cells. A previous report clearly indicated that Erk1/2 activation is associated functions of cell migration and invasion in human glioma cells (22). Hence, the authors tested galangin against the A172 glioma cell line for Erk1/2 activation in addition to the AKT signaling pathway. The results obtained from ERK1/2 activation and the AKT signaling pathway demonstrated that galangin effectively induced Erk1/2 phosphorylation whereas it failed to report a significant effect on AKT phosphorylation 


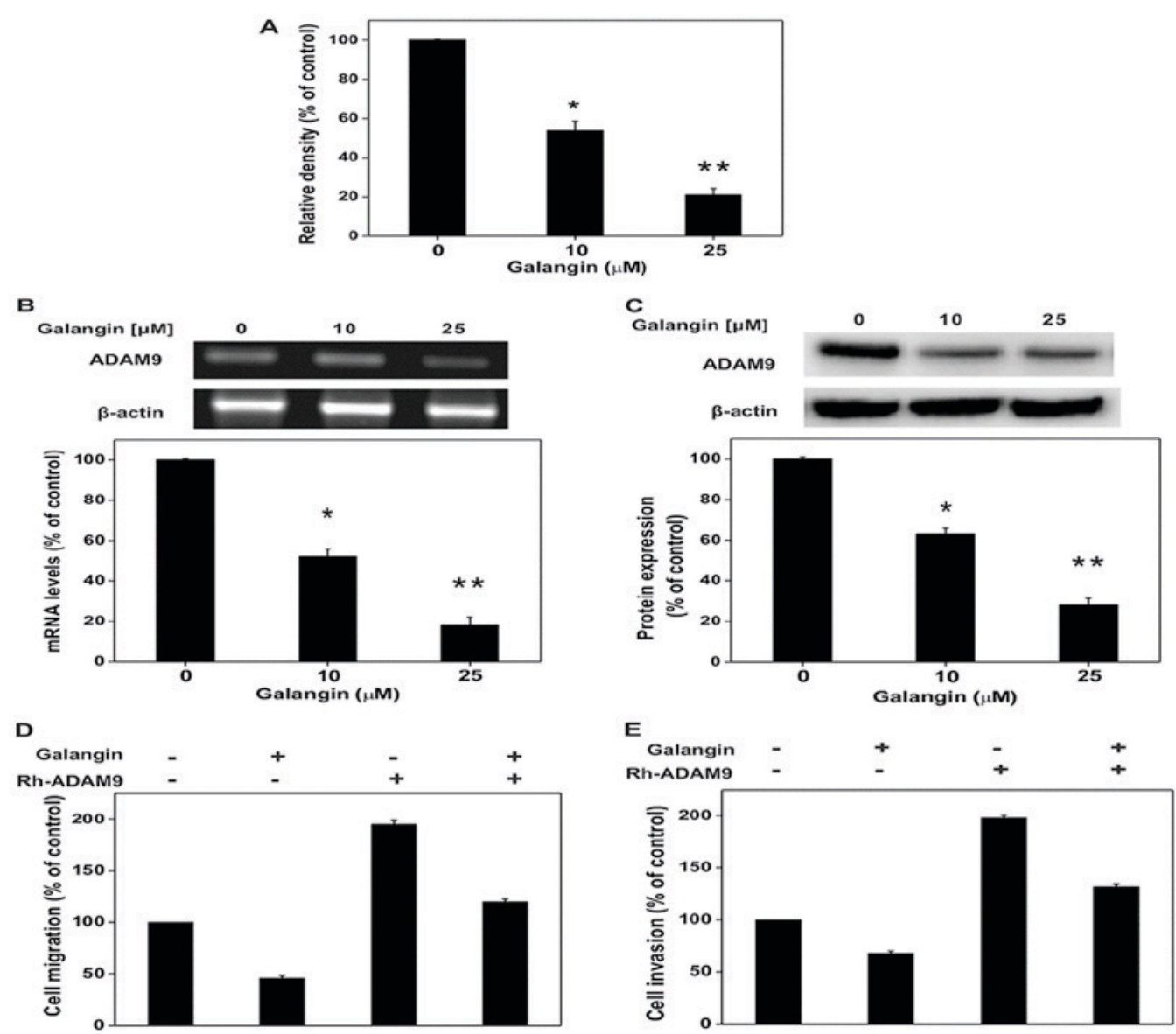

Figure 2. Expression, migration and invasion of ADAM9 in A172 cells following galangin treatment. (A) Densitometric analysis using a human proteinase array was performed by using A172 cell lysates treated 10 and $25 \mu \mathrm{M}$ for $24 \mathrm{~h}$. (B) Total mRNA and (C) protein expression in galangin treated A172 cells for $24 \mathrm{~h}$. (D) Cell migration and (E) cell invasion of A172 cells in the presence and absence of galangin and RhADAM9. The data are presented as the mean \pm standard error at three individual experiments. ${ }^{*} \mathrm{P}<0.05$; ${ }^{* *} \mathrm{P}<0.01$. vs. $0 \mu \mathrm{M}$ (Control).

(Fig. 3). Furthermore, no notable quantity of proteins (t-Erk1/2 and $\mathrm{t}-\mathrm{AKT}$ ) was obtained. All these data clearly evidenced the role of activation of Erk1/2 in the galangin inhibited the A172 cell migration and invasion mechanism.

Reduction of ADAM9 expression via Erk1/2 activation. In order to investigate the mechanistic pathway for galangin induced cell invasion inhibition, the authors first pre-treated the A172 glioma cell line with $15 \mu \mathrm{M}$ MEK inhibitor, U0126, for $\sim 3 \mathrm{~h}$ and then further added galangin for next $12 \mathrm{~h}$ before finally subjecting to western blot analysis, RT-qPCR and cell migration and invasion studies. Data obtained from these studies indicated that U0126 decreased galangin and triggered expression of Erk1/2, protecting galangin from protein hindrance and expressions of ADAM9 mRNA in A172 cells, as presented in Fig. 4A. Results from cell migration and cell invasion assays suggested that the pretreatment of MEK inhibitor completely blocked galangin-induced inhibition of A172 cell migration and invasions (Fig. 4B and C). Based on these results, ERK1/2 activation was identified to serve a specific function in galangin-mediated inhibition to cell migration and invasion. Moreover, A172 cells transiently transfected with siERK displayed effective reduction in total expression of ERK1/2 and terminated galangin-induced inhibition to ADAM9 expression (Fig. 5A). In addition, it was identified that siERK expression in A172 cells also blocked
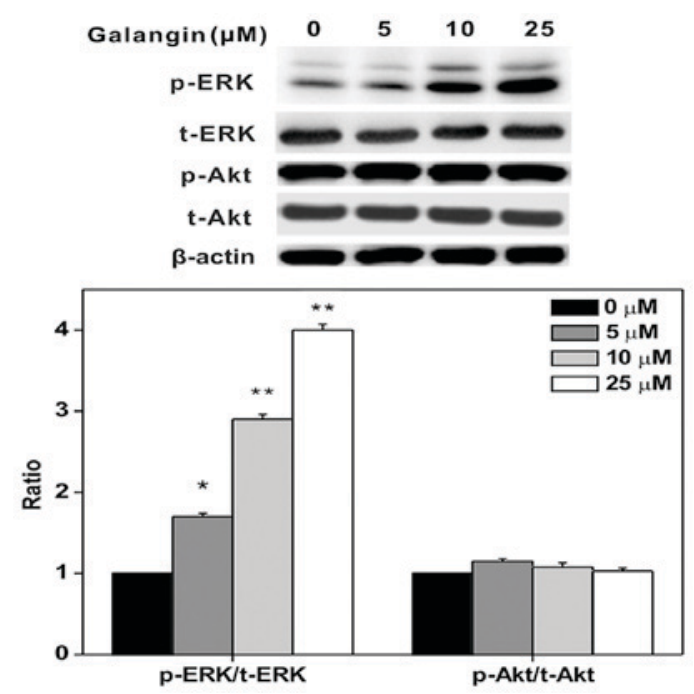

Figure 3. The expression of ERK1/2 and Akt following treating A172 cells with galangin for $24 \mathrm{~h}$. Western blotting was used to analyze the protein expression levels of p-ERK1/2, p-Akt, t-ERK1/2 and t-Akt with $\beta$-actin as the control. The data are presented as the mean \pm standard error at three individual experiments. ${ }^{*} \mathrm{P}<0.05 ;{ }^{* *} \mathrm{P}<0.01$. vs. $0 \mu \mathrm{M}$ (Control). ERK, extracellular signal-regulated kinase; Akt, protein kinase B.

galangin-induced inhibition to cell migration and invasion (Fig. 5B and C). All the obtained results clearly indicated that 

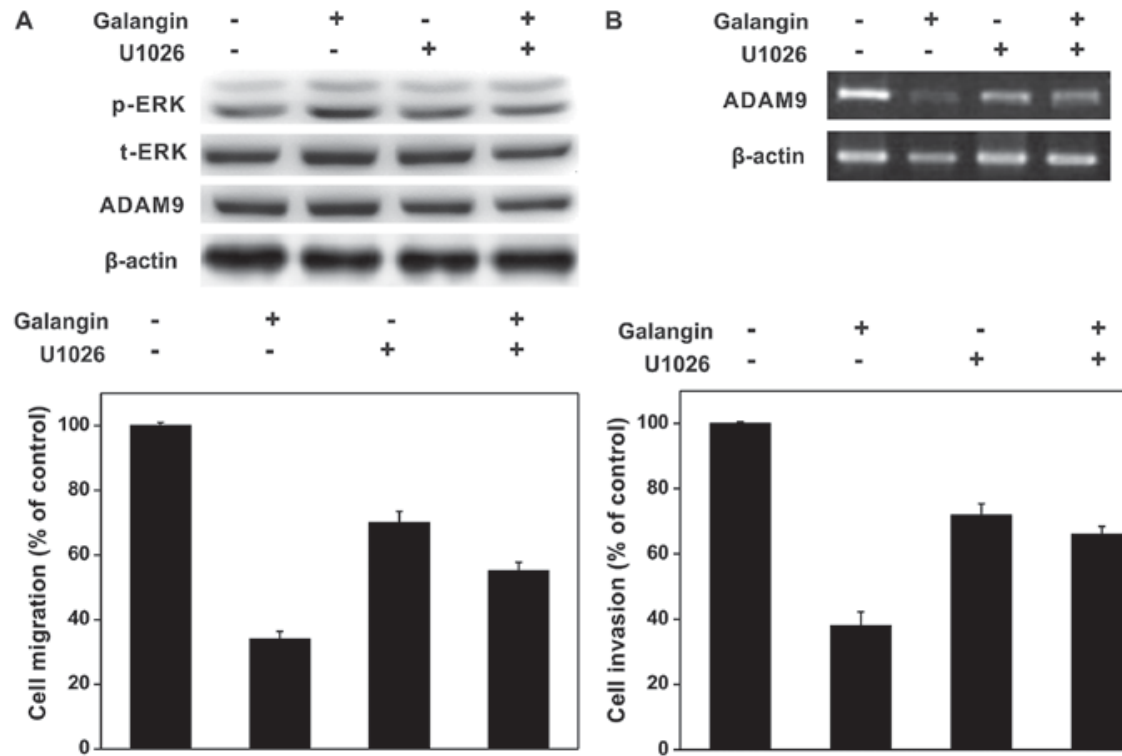

Figure 4. Inhibitory effect of U1026 and galangin on cell migration and cell invasion in A172 cells. The A172 cells were treated with $10 \mu \mathrm{M}$ U1026 for $2 \mathrm{~h}$ and allowed to grow for $24 \mathrm{~h}$ with or without galangin. Western blotting and reverse transcription-quantitative polymerase chain reaction analyses were performed from the cell lysates with $\beta$-actin as the control. (A) Cell invasion and (B) cell invasion following U1026 and galangin treatment were performed. ERK, extracellular signal-regulated kinase.

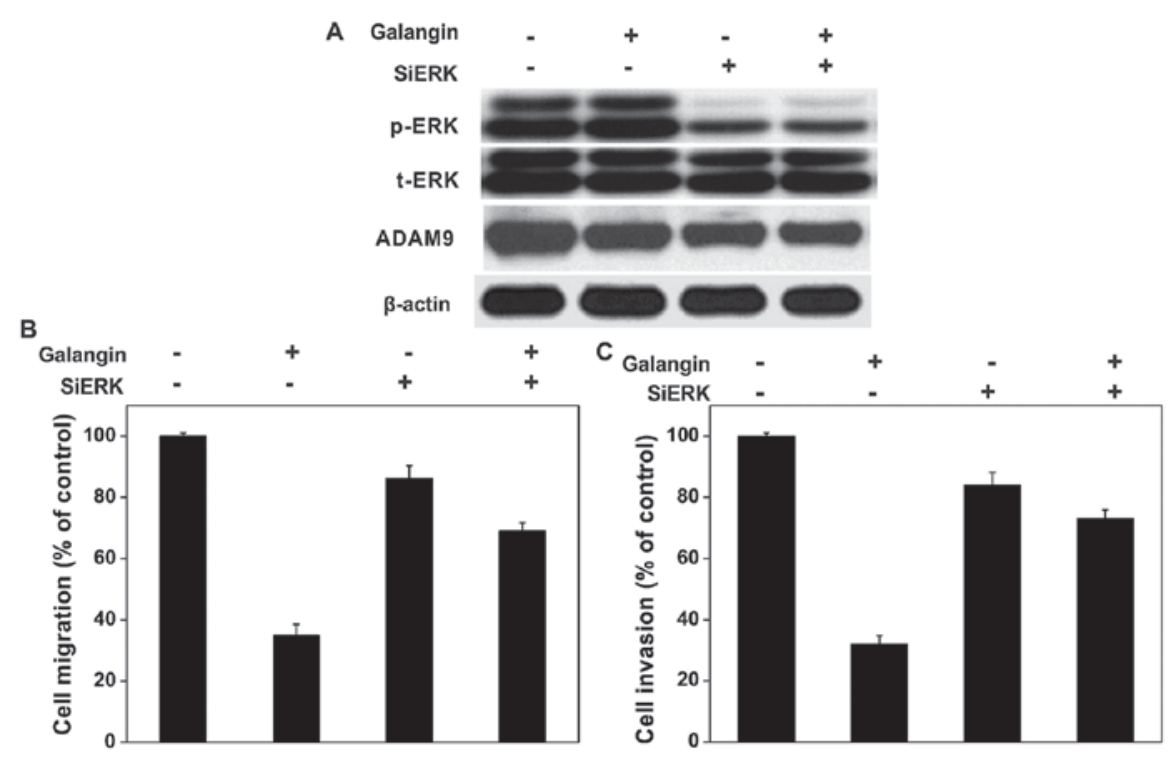

Figure 5. ERK1/2 knockdown effect of ADAM9 expression in galangin-treated A172 cells. A172 cells pretreated with siERK for $8 \mathrm{~h}$ and incubated for $48 \mathrm{~h}$ with or without galangin. (A) Western blotting was performed to analyze the protein expression. (B) Cell migration and (C) cell invasion assays were performed as described in methods section. ERK, extracellular signal-regulated kinase; siERK, small interfering ERK.

galangin hinders A172 glioma cell invasion via activation of ERK1/2.

\section{Discussion}

Regardless of developing novel therapies for different cancer types, the diagnosis for many cancers remains poor. Previously, researchers focused primarily on tumor research in order to reveal the underlying mechanisms on cancer metastasis and hence, various anti-cancer compounds have been identified. Flavonoids are a class of polyphenolic compounds that can display numerous positive effects on cancer treatments.
Galangin is one of the flavonoids that can exhibit pleiotropic anti-cancer properties and serve an important role in maintaining different molecular targets such as TNF- $\alpha, \mathrm{NF}-\kappa \mathrm{B}$, p38, ERK, JNK, PPAR $\gamma$, COX-2, ICAM-1 SMADs and interleukins (23-30). It is known that metastasis in tumors requires a sequence of signal transductions and, if drugs block these pathways, the cancer spread may be limited. Earlier reports have demonstrated that galangin induces apoptosis in different cancer cells in using different molecular mechanisms (21-23). Hepatocellular carcinoma cell proliferation is also hindered using galangin by inducing endoplasmic reticulum stress, AMPK activation and mitochondrial dysfunctions through 
Bax elevation and Bcl-2 reduction (31-33). Hence, a series of experiments were conducted using galangin to evaluate its anti-cancer potentials against the A172 glioma cell line.

Tumor metastasis is a complicated process in which tumor cells exhibit different characteristics such as elevated motility and invasive ability to finish the process. The important stage in this process is stromal extracellular matrix degradation (34). This process resulted in the cytokine and growth factor activation and produces signals to assist the tumor survival (35). Various proteases including ADAMTSs, ADAMs and MMPs are involved in these kinds of processes $(36,37)$ and hence, the authors aimed to target the ADAM9 gene in their studies. Among different cancer types, ADAM9 is considered as an oncogene (38-40). Some of the experimental results indicated that ADMA9 serves an important function in tumor metastasis. Data displayed in this work are the first illustrated results presenting galangin hindrance ability against human glioma tumor cell invasion mediated via ADAM9 expression. It is well known that the transduction molecules such as MAPKs and AKT are associated in maintaining various cellular processes such as cell proliferation, differentiation and apoptosis. However, some biological reports are controversial, depending on particular properties of different cancer cell types $(41,42)$. Many studies demonstrated that Erk1/2, NF-кB, FAK, PI3K/AKT Jnk1/2, p38 and MAPK also participate in glioma cell migration and invasion (43-46). In one report, treatment of sulforaphane hindered the cell migration and invasion against human glioma cells (U87MG and U373MG) mediated through the activation of Erk1/2. Data obtained from the present work also match with above result and hence, the authors revealed the participation of Erk1/2 activation along with hindrance of ADAM9 expression in galangin-inhibited cell invasion. From these experiments, the authors identified no direct proof to show that Erk1/2 can maintain or control ADAM9 expression. Hence, they decided to carry out new experiments to completely explore the correlation between Erk1/2 and ADAM9 expression in near future.

In conclusion, to the best of the authors' knowledge, the present study is the first to reveal that galangin possess the effective tendency to act as a potential drug to treat human glioma cancer mediated through Erk1/2 activation and ADAM9 expression pathways. In the near future, further experiments will be conducted to examine the complete connection between Erk1/2 and ADAM9 expression.

\section{Acknowledgements}

The present study was supported by the Tongji Medical College (grant no. TMC-28487/15), Huazhong University of Science and Technology (grant no. HUST-16).

\section{References}

1. Takahashi $\mathrm{H}$ and Teramoto A: Trial of targeting therapy against malignant glioma using monoclonal antibody. J Nippon Med Sch 71: 2-3, 2004.

2. Souhami R and Tobias J: Cancer and its management, 2 nd edition. Oxford, Blackwell Sciences, 1995.

3. Bleehen NM and Stenning SP: A medical research council trial of two radiotherapy doses in the treatment of grades 3 and 4 astrocytoma. Br J Cancer 64: 769-774, 1991.

4. Kitange GJ, Templeton KL and Jenkins RB: Recent advances in the molecular genetics of primary gliomas. Curr Opin Oncol 15: 197-203, 2003
5. Ramos S: Cancer chemoprevention and chemotherapy: Dietary polyphenols and signalling pathways. Mol Nutr Food Res 52: 507-526, 2008

6. Li BH and Tian WX: Presence of fatty acid synthase inhibitors in the rhizome of Alpinia officinarum hance. J Enzym Inhib Med Ch 18: 349-356, 2003.

7. Volpi N: Separation of flavonoids and phenolic acids from propolis by capillary zone electrophoresis. Electrophoresis 25 : 1872-1878, 2004

8. Sulaiman GM, Al Sammarrae KW, Ad'hiah AH, Zucchetti M, Frapolli R, Bello E, Erba E, D'Incalci M and Bagnati R: Chemical characterization of Iraqi propolis samples and assessing their antioxidant potentials. Food Chem Toxicol 49: 2415-2421, 2011.

9. Heo MY, Sohn SJ and Au WW: Anti-genotoxicity of galangin as a cancer chemopreventive agent candidate. Mutat Res 488: 135-150, 2001.

10. Cushnie TP and Lamb AJ: Assessment of the antibacterial activity of galangin against 4-quinolone resistant strains of Staphylococcus aureus. Phytomedicine 13: 187-191, 2006.

11. Gwak J, Oh J, Cho M, Bae SK, Song IS, Liu KH, Jeong Y, Kim DE, Chung YH and Oh S: Galangin suppresses the proliferation of $\beta$-catenin response transcription positive cancer cells by promoting adenomatous polyposis coli/Axin/glycogen synthase kinase-3 $\beta$-independent $\beta$-catenin degradation. Mol Pharmacol 79: 1014-1022, 2011.

12. Ha TK, Kim ME, Yoon JH, Bae SJ, Yeom J and Lee JS: Galangin induces human colon cancer cell death via the mitochondrial dysfunction and caspase-dependent pathway. Exp Biol Med (Maywood) 238: 1047-1054, 2013.

13. Murray TJ, Yang X and Sherr DH: Growth of a human mammary tumor cell line is blocked by galangin, a naturally occurring bioflavonoid, and is accompanied by down-regulation of cyclins D3, E, and A. Breast Cancer Res 8: R17, 2006.

14. Zhang HT, Luo H, Wu J, Lan LB, Fan DH, Zhu KD, Chen XY, Wen M and Liu HM: Galangin induces apoptosis of hepatocellular carcinoma cells via the mitochondrial pathway. World J Gastroenterol 16: 3377-3384, 2010

15. Zhang W, Lan Y, Huang Q and Hua Z: Galangin induces B16F10 melanoma cell apoptosis via mitochondrial pathway and sustained activation of p38 MAPK. Cytotechnology 65: 447-455, 2013.

16. Huang H, Chen AY, Rojanasakul Y, Ye X, Rankin GO and Chen YC: Dietary compounds galangin and myricetin suppress ovarian cancer cell angiogenesis. J Funct Foods 15: 464-475, 2015.

17. Bestwick CS and Milne L: Influence of galangin on HL-60 cell proliferation and survival. Cancer Lett 243: 80-89, 2006.

18. Szliszka E, Czuba ZP, Bronikowska J, Mertas A, Paradysz A and Krol W: Ethanolic extract of propolis augments TRAIL-induced apoptotic death in prostate cancer cells. Evid Based Complement Alternat Med 2011: 535172, 2011.

19. Wen M, Wu J, Luo H and Zhang H: Galangin induces autophagy through upregulation of p53 in HepG2 cells. Pharmacology 89: 247-255, 2012.

20. Wang G, Li Z, Tian N, Han L, Fu Y, Guo Z and Tian Y: miR-148b-3p inhibits malignant biological behaviors of human glioma cells induced by high HOTAIR expression. Oncol Lett 12: 879-86, 2016.

21. Kim YH, Shin EK, Kim DH, Lee HH, Park JH and Kim JK: Antiangiogenic effect of licochalcone A. Biochem Pharmacol 80: 1152-1159, 2010.

22. Green JA, Elkington PT, Pennington CJ, Roncaroli F, Dholakia S, Moores RC, Bullen A, Porter JC, Agranoff D, Edwards DR and Friedland JS: Mycobacterium tuberculosis upregulates microglial matrix metalloproteinase-1 and -3 expression and secretion via NF kappaB- and activator protein-1-dependent monocyte networks. J Immunol 184: 6492-6503, 2010.

23. Huh JE, Jung IT, Choi J, Baek YH, Lee JD, Park DS and Choi DY: The natural flavonoid galangin inhibits osteoclastic bone destruction and osteoclastogenesis by suppressing NF- $\kappa \mathrm{B}$ in collagen-induced arthritis and bone marrow-derived macrophages. Eur J Pharmacol 698: 57-66, 2013.

24. Jung YC, Kim ME, Yoon JH, Park PR, Youn HY, Lee HW and Lee JS: Anti-inflammatory effects of galangin on lipopolysaccharide-activated macrophages via ERK and NF- $\kappa$ B pathway regulation. Immunopharmacol Immunotoxicol 36: 426-432, 2014.

25. Wang Y, Wu J, Lin B, Li X, Zhang H, Ding H, Chen X, Lan L and Luo H: Galangin suppresses HepG2 cell proliferation by activating the TGF- $\beta$ receptor/Smad pathway. Toxicology 326: 9-17, 2014. 
26. Jung CH, Jang SJ, Ahn J, Gwon SY, Jeon TI, Kim TW and Ha TY: Alpinia officinarum inhibits adipocyte differentiation and high-fat diet-induced obesity in mice through regulation of adipogenesis and lipogenesis. J Med Food 15: 959-967, 2012

27. Lotito SB and Frei B: Dietary flavonoids attenuate tumor necrosis factor alpha-induced adhesion molecule expression in human aortic endothelial cells. Structure-function relationships and activity after first pass metabolism. J Biol Chem 281: 37102-371010, 2006.

28. Kim HH, Bae Y and Kim SH: Galangin attenuates mast cell-mediated allergic inflammation. Food Chem Toxicol 57: 209-216, 2013.

29. Choi JK and Kim SH: Inhibitory effect of galangin on atopic dermatitis-like skin lesions. Food Chem Toxicol 68: 135-141, 2014.

30. O'Leary KA, de Pascual-Teresa S, Needs PW, Bao YP, O'Brien NM and Williamson G: Effect of flavonoids and vitamin E on cyclooxygenase-2 (COX-2) transcription. Mutat Res 551: 245-254, 2004

31. Zhang HT, Luo H, Wu J, Lan LB, Fan DH, Zhu KD, Chen XY, Wen M and Liu HM: Galangin induces apoptosis of hepatocellular carcinoma cells via the mitochondrial pathway. World J Gastroenterol 16, 3377-3384, 2010

32. Su L, Chen X, Wu J, Lin B, Zhang H, Lan L and Luo H: Galangin inhibits proliferation of hepatocellular carcinoma cells by inducing endoplasmic reticulum stress. Food Chem Toxicol 62: 810-816, 2013

33. Zhang H, Li N, Wu J, Su L, Chen X, Lin B and Luo H: Galangin inhibits proliferation of HepG2 cells by activating $A M P K$ via increasing the AMP/TAN ratio in a LKB1-independent manner. Eur J Pharmacol 718: 235-244, 2013.

34. Pandey M, Mathew A and Nair MK: Global perspective of tobacco habits and lung cancer: A lesson for third world countries. Eur J Cancer Prev 8: 271-279, 1999.

35. Spira A and Ettinger DS: Multidisciplinary management of lung cancer. N Engl J Med 350: 379-392, 2004.
36. Sarkar FH and Li YW: Targeting multiple signal pathways by chemopreventive agents for cancer prevention and therapy. Acta Pharmacol Sin 28: 1305-1315, 2007.

37. Weng CJ and Yen GC: Chemopreventive effects of dietary phytochemicals against cancer invasion and metastasis: Phenolic acids, monophenol, polyphenol, and their derivatives. Cancer Treat Rev 38: 76-87, 2012.

38. Chetty C, Rao JS and Lakka SS: Matrix metalloproteinase pharmacogenomics in non-small cell lung carcinoma. Pharmacogenomics 12: 535-546, 2011.

39. López-Otín C, Palavalli LH and Samuels Y: Protective roles of matrix metalloproteinases: From mouse models to human cancer. Cell Cycle 8: 3657-3662, 2009.

40. Li M, Xiao T, Zhang Y, Feng L, Lin D, Liu Y, Mao Y, Guo S, Han N, Di X, et al: Prognostic significance of matrix metalloproteinase-1 levels in peripheral plasma and tumour tissues of lung cancer patients. Lung Cancer 69: 341-347, 2010.

41. Kim EK and Choi EJ: Pathological roles of MAPK signaling pathways in human diseases. Biochim Biophys Acta 1802: 396-405, 2010

42. Wagner EF and Nebreda AR: Signal integration by JNK and p38 MAPK pathways in cancer development. Nat Rev Cancer 9: 537-549, 2009.

43. Hennessy BT, Smith DL, Ram PT, Lu Y and Mills GB: Exploiting the PI3K/AKT pathway for cancer drug discovery. Nat Rev Drug Discov 4: 988-1004, 2005.

44. Yoon SO, Shin S, Lee HJ, Chun HK and Chung AS: Isoginkgetin inhibits tumor cell invasion by regulating phosphatidylinositol 3-kinase/Akt-dependent matrix metalloproteinase-9 expression. Mol Cancer Ther 5: 2666-2675, 2006.

45. Veit C, Genze F, Menke A, Hoeffert S, Gress TM, Gierschik P and Giehl K: Activation of phosphatidylinositol 3-kinase and extracellular signal-regulated kinase is required for glial cell line-derived neurotrophic factor-induced migration and invasion of pancreatic carcinoma cells. Cancer Res 64: 5291-5300, 2004.

46. Günther W, Skaftnesmo KO, Arnold H and Terzis AJ: Molecular approaches to brain tumour invasion. Acta Neurochir (Wien) 145: 1029-1036, 2003. 